\title{
Repeated Partnerships and Radical Innovation: Evidence from Wireless Gaming Market
}

\author{
Kerem GÜRSES iD a Pınar ÖZCAN iD b Feray ADIGÜZEL iD c \\ a La Salle Ramon Llull University, Barcelona, Spain. kerem.gurses@salle.url.edu \\ b University of Oxford, Saïd Business School, United Kingdom.cpozcan@gmail.com \\ c ferayadiguzel14@hotmail.com
}

\begin{tabular}{|c|c|}
\hline ARTICLE INFO & ABSTRACT \\
\hline $\begin{array}{l}\text { Keywords: } \\
\text { Repeated partnerships } \\
\text { Radical innovations } \\
\text { Mobile gaming alliances }\end{array}$ & $\begin{array}{l}\text { Purpose - Firms often form alliances to manage innovation activities with prior or new partners. However, } \\
\text { it is not clear whether repeated alliances might reduce or increase incremental versus radical innovations. } \\
\text { This paper investigates the effect of repeated partnerships on firm's innovations in a creative industry, } \\
\text { namely mobile gaming industry. Specifically, the effects of publisher and carrier partnerships on new game } \\
\text { releases with existing versus new genres. }\end{array}$ \\
\hline $\begin{array}{l}\text { Received } 21 \text { January } 2021 \\
\text { Revised } 12 \text { April } 2021 \\
\text { Accepted } 5 \text { June } 2021\end{array}$ & $\begin{array}{l}\text { Design/methodology/approach - An empirical research was conducted using US mobile gaming industry } \\
\text { data between 2003-2005 which covers the new games released in period after 3G introduction and before } \\
\text { smartphones. Thus, included mobile games belong to the same generation in terms of mobile internet } \\
\text { telecommunication technology. The effect of repeated partnerships between a publisher and a carrier on a } \\
\text { mobile game genre was empirically tested with logistic regression. }\end{array}$ \\
\hline $\begin{array}{l}\text { Article Classification: } \\
\text { Research Article }\end{array}$ & $\begin{array}{l}\text { Findings - Repeated partnerships lead to lower likelihood of radical innovation. The likelihood of radical } \\
\text { innovation was lower for a large size partner relative to small size partner. }\end{array}$ \\
\hline & $\begin{array}{l}\text { Discussion-- This research contributes two streams of research: strategic alliance research and research on } \\
\text { creative industries. The type of innovation repeated interactions lead to in creative industry context was } \\
\text { examined and partner size was also introduced as an important factor. This study gives advices on firms } \\
\text { who needs alliance and suggest to have more diverse portfolio to continue their radical innovations. }\end{array}$ \\
\hline
\end{tabular}

\section{INTRODUCTION}

In order to get competitive, firms need to focus on innovation in today's business world. As the innovation takes place more and more in networks of collaborating firms rather than individual firms, firms often create alliances to be able to collaborate on innovation activities (Powell et al., 1996) and how to manage and configure these alliances are becoming crucial. Indeed, firms often have repeated alliances with partners they have collaborated before for new product development (Phelps, 2010; Sampson, 2005). Although repeated collaborations have been studied with different outcomes (the length of partnership history by Cowan \& Jonard, 2009; firm performance by Goerzen, 2007; contractual detail by Vanneste \& Puranam, 2010), there is some uncertainty about whether there is a causal relationship between repeated partnerships and positive innovation outcomes, in particular, radical innovations. Therefore, this study will investigate how repeated partnerships of a firm will influence radical innovations when there is a power imbalance between the partners.

Prior research is undecided about how repeat partner collaboration influences innovation (Zheng \& Yang, 2015). On the one hand, some studies postulate that repeated partnerships may foster innovation due to lessened transaction costs and enhanced coordination (Vanneste \& Puranam, 2010; Wuyts et al., 2004; Zheng and Yang, 2015). On the other hand, other ones illustrated that repeated partnerships may slow down innovations due to adoption of inert mental models and prior trajectories (Goerzen, 2007; Laursen \& Salter, 2006; Uzzi \& Lancaster, 2003; Zheng and Yang, 2015). In addition, extant research does not take into consideration the boundary conditions of how repeat partnerships influence radical innovations and there are also inconsistencies in the research findings. For instance, Sampson (2005) established that repeated 


\section{K. Gürses - P. Özcan - F. Adıgüzel 13/2 (2021) 1177-1186}

partnerships positively affect firm's innovative performance, whereas another study proved no relationship between firm's repeated partnerships and exploratory innovations (Phelps, 2010).

In order to tackle the inconsistencies in extant research to study this relationship, the impact of repeated partnerships was explored by taking into consideration another dimension, when there is a power imbalance between the partners. Creative industry is the context of the study, specifically wireless gaming industry where the notion of familiarity of the new products may be equally as important as novelty, therefore we posit that the large partners, due to their potential conservatism may push smaller partners to go for more incremental innovation when they have repeated interactions.

To test formulated hypotheses, a sample of U.S. firms in wireless gaming industry was extracted that are part of the longitudinal dataset of 25267 different combinations of publishers, games, carriers, handset manufacturers, platform that took place in the industry from 2003 to 2005.

The research results show that publisher firms' repeated partnerships with wireless carriers reduces genre changes and in turn, induces the firms to have more incremental innovations. Another partner firm level variable was introduced: firm size. Repeated partnerships with larger firms also tend to lead to fewer radical innovations than repeated partnerships with smaller firms.

The contribution of current study to literature is to present a closer view of the impact of repeated partnerships on innovations by taking into account power imbalances and a partner level variable such as firm size. Our findings also speak to the creative industries, where they are frequently criticized for prizing familiarity over radical innovations (Roch, 2004).

\section{THEORETICAL BACKGROUND}

\subsection{Repeated partnerships}

Firms involve in repeated partnerships with past partners if they find these partners trustworthy and easy to cooperate with. In many cases, these types of previous relations end up to be long-term partnerships. Firms manage these long-term partnerships via relational governance or relational contracting, as these approaches focus on the ties between partners and in addition, their shared goals of exchanging information, continuity and maintaining goodwill between partners (Ring \& Van de Ven, 1992).

Repeated partnerships will offer some advantages to the firms. First of all, since those firms share a longer history, they will enjoy improved coordination due to repeated partnership. Coordination means allocation, management, and integration a set of interdependent tasks by firms (Gulati et al., 2012; Okhuysen \& Bechky, 2009; Holloway \& Parmigiani, 2016). For partners who have collaborated previously, bilateral investments in common communication platforms, equipment that is customized, and specific training may be justified (Bensaou \& Anderson, 1999; Poppo \& Zenger, 2002; Williamson, 1996). In addition, any co-developed routines to facilitate efficiency and productivity will improve coordination (Dyer \& Singh, 1998; Nelson\& Winter, 1982; Zollo, Reuer, \& Singh, 2002). Thus, task allocation and effectiveness enhance with bilateral investments and co-developed routines that are specific to the dyad. Moreover, repeated partnerships will improve collaboration. Collaboration is defined as joint learning and problem solving that are based on knowledge transfer (Holloway \& Parmigiani, 2016). Knowledge transfer will be greater and richer through language and common communication platforms (March \& Simon, 1958; Tunisi \& Zanfei, 1998). Partners who interact on a repeated basis will share their values and objectives and therefore mutual learning will be accelerated (Fiol \& Lyles, 1985; Hult, Ketchen, \& Arrfelt, 2007). Safeguards will be built from prior exchanges due to trust, preventing partners from appropriating knowledge for their own advantage (Hoetker \& Mellewigt, 2009).

Finally, repeated partnerships help in adapting dynamic situations since these situations are associated with uncertainty. These deeper relationships normally involve a mid-level governance approach, combining market flexibility with hierarchy and its coordination advantages, both of which are crucial when uncertainty increases (Gulati et al., 2005; Williamson, 1985). The repeated partnership will drive allies towards a future orientation and allow them to appreciate the benefits of collaboration in the long term to the extent that they may be accepting to handle some costs linked to the uncertainty and overall be more flexible (Holloway \& Parmigiani, 2016). Uncertainty may cause a conflictive environment and increase in renegotiations demands by parties, and these situations may be alleviated when partners have worked together on a prior basis (Jeffries \& Reed, 2000). As environmental conditions demand adaptation, repeated partners are in a better position to come up with joint arrangements to mutually adapt and make sure that their responses are coordinated (Holloway \& Parmigiani, 2016; Zaheer \& Venkatraman, 1995). 


\section{K. Gürses - P. Özcan - F. Adıgüzel 13/2 (2021) 1177-1186}

Notwithstanding the aforementioned advantages, repeated partnerships may be accompanied with some disadvantages. Firms may be subject to opportunistic behavior from repeated partners, as they may forego monitoring and formal contractual mechanisms in such relationships, which may lead to value-destroying behavior such as shirking or slacking (Williamson, 1985; Wuyts \& Geyskens, 2005). For instance, partners might find out about each other's weaknesses and their cost structures during their partnership, and could take advantage of this information for their own benefit (Anderson \& Jap, 2005). In addition, there is a risk of appropriation of knowledge of the other partner (Khanna, Gulati, \& Nohria, 1998; Noordhoff et al., 2011). Especially when partnership involves asset specificity, repeat partners may intentionally not deliver the performance needed as they may believe that it is not likely that their partners would be able to refashion these asset specific investments with another partner (Poppo et al., 2008).

Another disadvantage of repeated partnerships is not being able to spot better, alternative partners. Firms involved with a repeated partner may not consider looking for another partner if the current partner is acceptable (Jones, Hesterly, \& Borgatti, 1997; March \& Simon, 1958). Enacted routines due to the repeated partnership also lead to inertia, since it would be difficult and costly to reproduce new routines with another partner (Levinthal \& Fichman, 1988). When they remain in an alliance for an extended period of time, firms risk becoming over-embedded, and they may find it difficult to partner with new firms (Uzzi, 1997). Moreover, firms may refrain from disrupting strong personal relationships and eventually suffering the negative emotions that may come after subsequently (Anderson \& Jap, 2005).

\subsection{Repeated partnerships and radical innovation}

Considering these advantages and disadvantages from an innovation perspective, extant research has provided an incomplete account of how repeated partner collaboration affects innovation. As already said, improved coordination and decreased transaction costs were discussed as advantages of repeated partnerships (Vanneste \& Puranam, 2010; Wuyts et al., 2004; Zheng and Yang, 2015), locking firms into inert mental models and earlier trajectories was stated as disadvantages of it (Goerzen, 2007; Laursen \& Salter, 2006; Uzzi \& Lancaster, 2003; Zheng and Yang, 2015). This study argues that more studies should be conducted to capture the tension between the benefits and potential costs related with repeated partnerships. Second, previous studies have rarely explored if there are boundary conditions with respect to the impact of repeated partnerships on radical innovations (Zheng \& Yang, 2015). To illustrate, Sampson (2005) established that a firm's repeated partnerships improve firm's innovation performance, whereas Phelps (2010) presented that a firm's repeated partnerships do not have a bearing on exploratory innovations.

In sum, as reviewed in the previous literature, although repeated partnerships may help manage the uncertainty associated with radical innovations (Zheng \& Yang, 2015), they may also inhibit the development of radical innovations, since over-embeddedness in repeated partnerships may make their adaptation process rather incremental and local (Rosenkopf \& Nerkar, 2001). When collaborating with a prior partner, the communication and coordination routines, due to rigidity, may start excluding new ideas, ending with a familiarity trap. Repeated partnerships have the possibility of locking the firms into earlier mental models if the partners which are familiar unconsciously interact using previous patterns (Skilton \& Dooley, 2010). The alliance may favor exploitation instead of exploration (Koza and Lewin, 1998). In a similar vein, if the repeated alliance takes place between firms with a power imbalance, we argue that since larger firms, focusing on profit maximization, will have a more rational and conservative approach to innovation (Tschang, 2007), smaller partners will be captured in the conservatism of the larger partner leading to a spiral of incremental innovations over time.

Thus, we propose that:

Hypothesis 1: Repeated partnerships will lead to fewer radical innovations when there is a power imbalance between the partners.

In addition, we also argue that, this relationship will be influenced by partner size. Larger firms will tend to push even more towards incremental innovation over the course of repeated interactions, as their level of conservatism may increase. Therefore, we expect:

Hypothesis 2: Repeated partnerships with larger firms will lead to fewer radical innovations compared to repeated partnerships with smaller firms. 


\section{K. Gürses - P. Özcan - F. Adıgüzel 13/2 (2021) 1177-1186}

\section{RESEARCH CONTEXT}

\subsection{Creative industries}

The creative industries include companies that produce, and distribute products which appeal to aesthetic or expressive tastes rather than to the functional characteristics of customer needs (Peterson \& Berger, 1996; Hirsch, 2000; Lampel, Lant, \& Shamsie, 2000). For instance, films, books, fashion, music and games are creative products. According to Tschang (2007), creative industry products are known for having (1) a hits orientation (i.e., a small number of products that make a larger amount of the company revenues); (2) having a shorter product life cycle in the market (Epstein 2005, Hirsch, 2000, Robins 1993); and (3) difficulties in envisaging product success (De Vany 2004). Because of all these factors, the nature of new product decisions are essentially conservative, giving room to incremental innovations (those innovations that typically encompass minor tweaking to the products' components). Nonetheless, this is paradoxical, since as Lampel et al. (2000: 266) states, "Competition in creative industries is driven by a search for novelty. However, while consumers expect novelty in their creative goods, they also want novelty to be accessible and familiar." Thus, testing our hypothesis in a context where firms will need to balance novelty and familiarity will reveal interesting and novel results.

The U.S. wireless games industry is the research context of this study. Video games in general are sophisticated products that use a combination of advanced software technology with interactive content. Wireless games have an important share of this market, in 2016, they contributed to roughly 12,1 billion USD revenues, about $17 \%$ of the overall gaming revenues. Wireless games are downloaded by the customer to their mobile phone with a connection supplied by an internet service provider. This industry consists of several different type of companies which are often interdependent, including game publishers (e.g., THQ), wireless carriers (e.g., Verizon, AT\&T), brand owners (e.g., NewLine Cinema), game developers, game platform providers (e.g., Sun), and handset makers (e.g., Nokia). Although power dynamics have shifted over time, and platforms such as IOS and Android gained prominence, at the time of our case, wireless carriers had a much more power advantage over their publisher partners due to their size and their privileged position having direct access to the final customers. Since the research focus is innovation in this industry, although we can measure innovation in various ways within creative industries, (for a good example, see, Sternberg, 1998), we decided to incorporate measures inherent to the games industry, which requires measures related to genres (Tschang, 2007).

\subsection{Genre change as radical innovation in wireless gaming}

Genre is a tool, generally used to conceptually categorize creative products, predominantly in the areas of popular culture, video games, visual art, literature, music, and film. It describes in what way artists, their peer groups, and their audiences build a common understanding for the creative output (Becker, 1982; Bourdieu, 1993).

A particular genre within gaming industry can be exclusively defined by a certain combination of different components. Typically, these are the following: The form of gameplay is defined as "the formalized interaction that occurs when players follow the rules of a game and experience its system through play" (Salen \& Zimmerman, 2003: 303) and at times it encompasses the genre-specific story or background. For instance, the common component in role-playing games are the heroic mission and the fantasy setting. The game's design usually needs to capture all these features (with gameplay emanating from the game's design), and thus establishes the uniqueness of the game (Tschang, 2007).

A way to measure if a new game is an innovation within the gaming industry is to use the genre lens. On the one hand, a new genre can be defined as a radical innovation. On the other hand, games that imitate established forms of gameplay, story, visual styles, and integrate these components in similar ways as before while doing some changes to the existing genre were stated as incremental innovations (Tschang, 2007). According to Peltoniemi (2009) and Cappetta et al. (2006), innovations can be categorized into technological and stylistic in cultural and creative industries in addition to incremental and radical innovation. Stylistic innovations in a game could be creation of new genres, characters, stories, styles and gameplays (Peltoniemi, 2009). 
K. Gürses - P. Özcan - F. Adıgüzel 13/2 (2021) 1177-1186

\section{RESEARCH DESIGN and METHOD}

This study has employed empirical research with a longitudinal approach using secondary data. As described above, the research context is the U.S. wireless gaming and research population covers publisher and carrier pairs. The focus is the repeated partnerships between game publishers and wireless carriers. These actors are interdependent, because carriers, in order to promote the use of their networks, will need attractive content such as games, while game publishers need the help of the wireless carriers in order to access consumers. This study attempts to provide a closer view at the game launches and partnerships within industry taking into account the major industry actors such as game publishers, wireless carriers, handset manufacturers and platform providers.

Publishers create wireless games and provide them to the carriers (or distributors) and note that they can provide the same game to different carriers. Handset manufacturers provide game-capable phones to the carrier. We test the hypotheses using a longitudinal data developed by Wireless gaming review, a major trade journal of the industry, which covers the wireless gaming industry between the years 2003 and 2005. This period is after 3G introduction in July 2002 in USA and before smartphones. 3G represents the third generation of wireless mobile telecommunications technology which started the age of mobile internet and open the way for the rise of smartphones. This interesting period was selected because of data availability, mobile games industry structure and to keep the same generation of mobile games in the sample.

Since the mobile phone technology, mobile services, wireless mobile telecommunications technology, and innovations in mobile games evolve parallel to each other, studying this period is interesting. Technological developments play a major role in game development as a major component of the creative process. Additionally, the games industry was discussed as deviating from the traditional industry-life cycle theory (Peltoniemi 2009). Innovations were free of market age in the games industry because innovation activity does not necessarily stabilize as the market ages (Peltoniemi 2009).

The resulting sample that is being used in this research is composed of 1672 games, 236 publishers, nine carriers and sixteen handset manufacturers. From the dataset of 25267 different combinations of publishers, games, carriers, handset manufacturers, and platform, repeat partnerships information of publisher-carrier for each game of a publisher was extracted. Updated versions of the same game on different time points were treated as the same game. The sample unit of analysis is at publisher-game level and there are 1672 games in the used sample and it is a cross-section data. Firstly, all games were coded based online information about genre, and manually checked with the game descriptions by the student assistant who was an expert player of mobile games. Twenty genres were identified for the games. Sports, action and casual genres have the first three highest number of games, specifically 301, 279 and 149 games. Educational, family, and dice genres have the lowest number of games, specifically 4,5 and 26 games.

The dependent variable for hypothesis 1 and 2 is genre change. Genre change is coded as 0 if a publisher continues with the same genre while launching games or as 1 if a publisher changes a genre while launching a new game. While we used genre change as the dependent variable in logistic regression model, independent variables were change in carrier ( 1 or 0 ) indicating whether or not a publisher did conduct a partnership with a different carrier other than the primary one, total number of partnerships of different carriers (take values of 1-9), total number of handset versions which was offered per games, number of repeated partnerships with a large, medium and small carrier, and duration of a game. Each carrier has been classified according to an ordinary scale (A, B, C) that takes into consideration the subscriber size of the carrier. Rank A has been assigned to the carriers that have the largest subscriber size (Verizon Wireless, Sprint PCS, Cingular, AT\&T Wireless) while rank B refers to carriers with medium subscriber size (T-mobile, Nextell), and rank C to mostly regional carriers with small subscriber size (Alltel, Cellular South, Metro PCS). We categorized each publisher relying on number of games released and created three dummy variables. Small publishers were defined as publishers who released one to three games. Medium size publishers were defined as publishers who released four to ten games. Large size publishers were defined as publishers who released more than eleven games. Total number of handset manufacturers per games and average duration of a game were also included as a control variable. 


\section{K. Gürses - P. Özcan - F. Adıgüzel 13/2 (2021) 1177-1186}

Firstly, descriptive statistics and correlation matrix were inspected before the analysis. A logistic regression model was ran with the IBM SPSS Statistics 25 to explore the determinants of genre strategy in the wireless gaming industry and to examine the suggested hypotheses.

\section{FINDINGS}

We display the descriptive of publishers and games in Table 1. The table indicates how the U.S. wireless gaming industry changed rapidly just in three years. The number of publishers increased $50 \%$ from 2003 to 2004 while it decreased 37\% from 2004 to 2005. The number of new publishers who entered the market first time was 92 in 2004, number of publishers who exited the market was 85. Number of games which were available in the market was the highest in 2004.

Table 1. Descriptive statistics over time $(n=25267 ; n$ (publisher-game pair) $=1672)$

\begin{tabular}{lccc}
\hline & & Year & \\
& 2003 & 2004 & 2005 \\
\hline Number of publishers & 136 & 205 & 730 \\
Number of games & 4680 & 13526 & 8061 \\
Number of unique games & 849 & 1262 & 10 \\
Number of entry (publisher) & - & 92 & 85 \\
Number of exit (publisher) & - & 23 & \\
\hline
\end{tabular}

The multicollinearity issue was inspected by inspecting the sample correlation matrix (Table 2) and the variance-inflation factors (VIF). Two models were fitted (Table 3). Model 1 included the main variables of repeated partnerships with a carrier. Model 2 included additional game- and publisher-specific control variables. All VIF values were lower than the recommended cutoff value, 10. The averaged VIF was equal to 2,22 for Model 1 and 3,65 for the Model 2. So, there was no multicollinearity problem.

Table 2. Associations among variables

\begin{tabular}{llllllllllll}
\hline $\begin{array}{l}\text { Spearman } \\
\text { Correlations }\end{array}$ & $(1)$ & $(2)$ & $(3)$ & $(4)$ & $(5)$ & $(6)$ & (7) & (8) & (9) & (10) & (11)
\end{tabular}

\begin{tabular}{llll}
\hline \hline (1) Genre change & 1,00 & & \\
\hline (2) Change in carrier &, $22^{* *}$ & 1,00 & \\
\hline (3) \# of different carrier &,$- 08^{* *}$ &, $20^{* *}$ & 1,00
\end{tabular}

(4) Repeated partnerships with a , $02,16^{* *}, 55^{* *} \quad 1,00$

small carrier

(5) Repeated partnerships with a $-, 06^{*}, 03 \quad 0,28^{* *}-, 11^{* *} \quad 1,00$

medium carrier

(6) Repeated partnerships with a $-, 07^{* *}, 13^{* *}, 72^{* *}, 36^{* *} \quad-, 12^{* *} \quad 1,00$

large size carrier

\begin{tabular}{|c|c|c|c|c|c|c|c|c|c|}
\hline (7) Game Duration &,- 04 &, $08^{* *}$ &, $51^{* *}$ & $33^{* *}$ &,- 04 & $43^{* *}$ & 1,00 & & \\
\hline (8) Total handset &,$- 06^{*}$ & $14^{* *}$ &, $71^{* *}$ & $42^{* *}$ & $24^{* *}$ & $79^{* *}$ &, $33^{* *}$ & 1,00 & \\
\hline (9) Small Publisher &,$- 08^{* *}$ & ,03 &,$- 19^{* *}$ &,$- 08^{* *}$ &,$- 08^{* *}$ &,$- 15^{* *}$ &,$- 12^{* *}$ &,$- 16^{* *}$ & 1,00 \\
\hline (10) Medium Publisher & $18^{* *}$ &, $09^{* *}$ &,$- 10^{* *}$ &, $11^{* *}$ &,$- 09^{* *}$ &,$- 10^{* *}$ &,$- 10^{* *}$ &,$- 07^{* *}$ & $-, 17^{* *} \quad 1,00$ \\
\hline (11) Large Publisher &,$- 09^{* *}$ & $-10^{* *}$ & $22^{* *}$ &,$- 02^{* *}$ & $13^{* *}$ & $19^{* *}$ & $16^{* *}$ & $18^{* *}$ &,$- 60^{* *}-, 69^{* *}$ \\
\hline
\end{tabular}

In Model 1, the effects of carrier change, total number of partnerships with a different carrier, number of repeated partnerships with larger, medium and small size carrier on the likelihood of genre change was investigated.

The chi-square value of 125,81 was significant $(p<0,05)$ indicates that Model 1 , all together fits significantly better than an empty model (i.e., a model with no predictors). Besides, there was a good model fit because a Hosmer and Lemeshow test was not significant (a Hosmer-Lemeshow chi-squared $=2,265, p=0,97$ ) and 


\section{K. Gürses - P. Özcan - F. Adıgüzel 13/2 (2021) 1177-1186}

Nagelkerke R-square was equal to 0,102. Change in carrier, total partnership carrier worked and number of repeated partnerships with a small size carrier (C) were significant because p-value is less than 0,05; thus $\mathrm{H} 1$ and $\mathrm{H} 2$ confirmed. Repeated partnerships with a large and medium sizer partner were not significant $(\mathrm{p}=$ $0,301, p=0,207$, respectively). When a publisher changes partner carrier for a new game, versus stay with a primary partner, the log odds of genre change increases by 1,542. For every one unit change in total number of partnerships carrier, the log odds of genre change (versus same genre as prior one) decreases by 0,411 . For a one unit change in repeated partnership with a small size carrier, the log odds of genre change (versus same genre as prior one) increases by 0,122 .

Model 2 with additional predictors has also good fit (a Hosmer-Lemeshow chi-squared $=8,771, \mathrm{p}=0,36$ ) and Nagelkerke R-square was equal to 0,232. The results in Model 2 were supporting the findings in Model 1. While the likelihood of genre change decreased significantly with change in total number of partnerships with different carriers $(B=-0,357, p<0,001)$, it increased significantly with change in carrier $(B=1,745, p<0,001)$. Repeated partnerships with small, medium and large partners were all significantly influencing the probability of genre change (Blarge $=0.093, p=0,041$; $B_{\text {medium }}=0,104, p=0,033 ; B_{\text {small }}=0,116, p=0,011$ ). Thus, the probability of genre change was the highest for repeated partnerships with a small partner. The equality of coefficients of partnership with a large size vs small carrier (for H2) was tested in STATA 15. The test was significant (chisquare $(2)=11.60, p=0.003$ ), indicating they are not equally effective. Thus, the conclusions for $\mathrm{H} 1$ and $\mathrm{H} 2$ are consistent when additional predictors were added. Additionally, when total handset and being a small publisher (vs large size publisher) decreased the likelihood of radical innovation significantly, being a medium size publisher (compare to large size publisher) increased the likelihood of genre change. Among genre categories, action, arcade, card, puzzle, and sports decreased significantly the likelihood of genre change compare to kids genre.

Table 3. Results of Model 1 and 2 (Genre change is the dependent variable: 1 change, 0 no change)

\begin{tabular}{lccc}
\hline & \multicolumn{3}{c}{ Model 1 } \\
\cline { 2 - 4 } &,- 502 & p-value & Exp(B) \\
\hline Constant & 1,542 &, 000 &, 606 \\
\hline Change in carrier &,- 411 &, 000 &, 663 \\
\hline Total \# of different carrier &, 027 &, 301 & 1,027 \\
\hline \# of repeated partnerships & & & \\
with a large carrier &, 041 &, 207 & 1,041 \\
\hline \# of repeated partnerships & & & \\
with a medium carrier &, 122 &, 001 & 1,129 \\
\hline \# of repeated partnerships & & & \\
with a small size carrier & & & \\
\hline Total handset & & & \\
\hline Game Duration & & \\
\hline Small Publisher & & \\
\hline Medium Publisher & & \\
\hline Genre: Action & & \\
\hline Genre: Adventure & & \\
\hline Genre: Arcade & & \\
\hline Genre: Board & & \\
\hline Genre: Card & & \\
\hline Genre: Casino & & \\
\hline Genre: Educational & & \\
\hline Genre: Music & & \\
\hline Genre: Puzzle & & \\
\hline Genre: Racing & & \\
\hline Genre: Roleplaying & & \\
\hline Genre: Simulation & & \\
\hline Genre: Sports & & \\
\hline
\end{tabular}

\begin{tabular}{|c|c|c|}
\hline \multicolumn{3}{|c|}{ Model 2} \\
\hline B & p-value & $\operatorname{Exp}(B)$ \\
\hline ,337 & , 400 & 1,401 \\
\hline 1,745 & ,000 & 5,724 \\
\hline,- 357 & ,000 & ,700 \\
\hline ,093 & ,041 & 1,098 \\
\hline 104 & ,033 & 1,110 \\
\hline 116 & 011 & 1,123 \\
\hline-024 & ,032 & ,976 \\
\hline ,000 & ,815 & 1,000 \\
\hline,- 792 & ,000 & ,453 \\
\hline ,669 & , 000 & 1,953 \\
\hline$-1,353$ & ,001 & 258 \\
\hline,- 725 & ,093 & ,484 \\
\hline$-1,273$ & ,004 & ,280 \\
\hline-231 & 631 & 794 \\
\hline$-1,217$ & ,007 & ,296 \\
\hline,- 171 & ,735 & ,843 \\
\hline 1,296 & ,294 & 3,653 \\
\hline ,415 & ,496 & 1,514 \\
\hline,- 882 & ,037 & ,414 \\
\hline,- 453 & ,297 & ,635 \\
\hline ,145 & 800 & 1,157 \\
\hline ,047 & ,927 & 1,049 \\
\hline$-1,805$ & ,000 & ,165 \\
\hline
\end{tabular}


K. Gürses - P. Özcan - F. Adıgüzel 13/2 (2021) 1177-1186

\begin{tabular}{|c|c|c|c|}
\hline Genre: Strategy & 207 & 717 & 1,230 \\
\hline Genre: Trivia &,- 112 & 821 & 894 \\
\hline Genre: Word &,- 638 & ,205 &, 528 \\
\hline Genre: Casual &,- 519 & ,214 &, 595 \\
\hline Genre: Dice & 1,199 & ,094 & 3,318 \\
\hline Genre: Family & 1,449 & ,226 & 4,260 \\
\hline
\end{tabular}

Note. Kids is the reference genre category. Large publisher is the reference publisher category.

\section{Discussion and Conclusion}

Our focus in this study was to explore the relationship among repeated partnerships, partner sizes and radical innovations in a creative industry, specifically mobile gaming industry. Since changing a mobile genre for a new game requires new skills set and time and new-to-the-company, it is regarded as radical innovation, while creating a new game in the previous game genre was defined as incremental innovation.

Our findings suggest that having repeated partnerships with the same carriers exerts a strong influence in the genre strategies of game publishers, eventually ending up with a reduction of genre change and therefore radical innovation. Furthermore, aligned with our expectations, the results show that repeated partnerships with larger carriers lead to fewer genre changes, meaning that less radical innovation takes place when publishers have repeated partnerships with larger partners compared to smaller partners. After a focal company changes a carrier partner, the likelihood of radical innovation increases. As expected, small publishers released less radical innovations compare to larger publishers. Thus, firm size positively influences radical innovations in creative industry as well. Publishers produce action, arcade, card, puzzle, and sports games released few radical innovations compare to kids genre. These games were also the most popular games released in the market.

This study holds implications for both strategic alliance research and research on creative industries. We provide insights on the factors influencing the genre strategies of companies and on what type of innovation repeated interactions lead to in the creative industry context. Partner size was also introduced as a factor related to, which also influences genre change and subsequently radical innovation. The findings of this paper are relevant for firms pursuing alliances, although on paper, they may benefit from this repeated interaction due to its collaborative advantages, it may make sense to have a more diverse portfolio of alliance partners to be able to continue with radical innovation especially if there is the presence of power imbalance between partners. Some limitations should be noted. Game developers produce a new game which should be different from the old ones either by content or technology. In this paper, we focused on the genre of new game released by a publisher which is a stylistic innovation which could be incremental versus radical. That is why, we focused on new games in the period 2003-2005 with the same generation. Future research can investigate the findings of this research on the latest generation of mobile games or might include technological innovations as well with a longer longitudinal data. Future research should focus on other partner focused factors, such as age/experience of the partner, which may have a substantial impact on innovation generally, and radical innovation on a particular basis. Pursuing this line of research may advance our understanding of what the right level of repeated alliances would be for a given firm and flesh out its implications. 


\section{K. Gürses - P. Özcan - F. Adıgüzel 13/2 (2021) 1177-1186 \\ References}

Anderson, E. and Jap, S. D. (2005). “The dark side of close relationships”, MIT Sloan Management Review, 46(3), 75.

Becker, H. S. (1982). Art worlds. Univ of California Press.

Bourdieu, P. (19930. Sociology in question (Vol. 18). Sage.

Bensaou, M. and Anderson, E. (1999). "Buyer-supplier relations in industrial markets: when do buyers risk making idiosyncratic investments?", Organization Science, 10(4), 460-481.

Cappetta, R., Cillo P., and Ponti A. (2006). "Convergent Designs in Fine Fashion: An Evolutionary Model for Stylistic Innovation," Research Policy, 35 (9), 1276-90

Cowan, R. and Jonard, N. (2009). "Knowledge portfolios and the organization of innovation networks", Academy of Management Review, 34(2), 320-342.

De Vany, A. (2004). Hollywood economics: How extreme uncertainty shapes the film industry. Routledge.

Dyer, J. H. and Singh, H. (1998). “The relational view: Cooperative strategy and sources of interorganizational competitive advantage", Academy of Management Review, 23(4), 660-679.

Epstein, E. J. (2005). The Big Picture: The New Logic of Money and Power in Hollywood. Random House, New York.

Fiol, C. M. and Lyles, M. A. (1985). “Organizational learning”, Academy of Management Review, 10(4), 803-813.

Goerzen, A. (2007). "Alliance networks and firm performance: The impact of repeated partnerships", Strategic Management Journal, 28(5), 487-509.

Gulati, R., Wohlgezogen, F., and Zhelyazkov, P. (2012). "The two facets of collaboration: Cooperation and coordination in strategic alliances", Academy of Management Annals, 6(1), 531-583.

Hirsch, P. M. (2000). "Cultural industries revisited”, Organization science, 11(3), 356-361.

Hoetker, G. and Mellewigt, T. (2009). “Choice and performance of governance mechanisms: matching alliance governance to asset type", Strategic Management Journal, 30(10), 1025-1044.

Holloway, S. S. and Parmigiani, A. (2016). "Friends and Profits Don't Mix: The Performance Implications of Repeated Partnerships." Academy of Management Journal, 59(2), 460-478.

Hult, G. T. M., Ketchen, D. J., and Arrfelt, M. (2007). "Strategic supply chain management: Improving performance through a culture of competitiveness and knowledge development", Strategic Management Journal, 28(10), 1035-1052.

Jeffries, F. L. and Reed, R. (2000). "Trust and adaptation in relational contracting", Academy of Management Review, 25(4), 873-882.

Jones, C., Hesterly, W. S., and Borgatti, S. P. (1997). "A general theory of network governance: Exchange conditions and social mechanisms", Academy of Management Review, 22(4), 911-945.

Khanna, T., Gulati, R., and Nohria, N. (1998). “The dynamics of learning alliances: Competition, cooperation, and relative scope", Strategic Management Journal, 193-210.

Koza, M. P., and Lewin, A. Y. (1998). "The co-evolution of strategic alliances", Organization Science, 9(3), 255264.

Lampel, J., Lant, T., and Shamsie, J. (2000). "Balancing act: Learning from organizing practices in cultural industries", Organization Science, 11(3), 263-269.

Laursen, K., and Salter, A. (2006). "Open for innovation: the role of openness in explaining innovation performance among UK manufacturing firms", Strategic Management Journal, 27(2), 131-150.

Levinthal, D. A., and Fichman, M. (1988). "Dynamics of interorganizational attachments: Auditor-client relationships", Administrative Science Quarterly, 345-369.

March, J. G., and Simon, H. A. (1958). Organizations. New York, NY: Wiley.

Nelson, R..R S. G. Winter (1982). An Evolutionary Theory of Economic Change. Cambridge, Mass.: Harvard University Press.

Noordhoff, C. S, Kyriakopoulos, K., Moorman, C.,Pauwels, P., and Dellaert, B. G. (2011). The bright side and dark side of embedded ties in business-to-business innovation. Journal of Marketing, 75(5):34-52.

Okhuysen, G. A., and Bechky, B. A. (2009). "10 coordination in organizations: An integrative perspective", The Academy of Management Annals, 3(1), 463-502.

Peltoniemi, M. (2009). Industry life-cycle theory in the cultural domain: Dynamics of the Games Industry. Tampere: Tampere University of Technology 


\section{K. Gürses - P. Özcan - F. Adıgüzel 13/2 (2021) 1177-1186}

Peterson, R. A., and Berger, D. G. (1996). "Measuring industry concentration, diversity, and innovation in popular music", American Sociological Review, 61(1), 175-178.

Phelps, C. C. (2010). "A longitudinal study of the influence of alliance network structure and composition on firm exploratory innovation", Academy of Management Journal, 53(4), 890-913.

Poppo, L., and Zenger, T. (2002). "Do formal contracts and relational governance function as substitutes or complements?", Strategic Management Journal, 23(8), 707-725.

Poppo, L., Zhou, K. Z., and Zenger, T. R. (2008). "Examining the conditional limits of relational governance: specialized assets, performance ambiguity, and long-standing ties", Journal of Management Studies, 45(7), 1195-1216.

Powell, W. W., Koput, K. W., and Smith-Doerr, L. (1996). "Interorganizational collaboration and the locus of innovation: Networks of learning in biotechnology", Administrative Science Quarterly, 116-145.

Ring, P. S., and Van de Ven, A. H. (1992). "Structuring cooperative relationships between organization", Strategic Management Journal, 13(7), 483-498.

Robins, J. A. (1993). "Organization as strategy: Restructuring production in the film industry", Strategic Management Journal, 14 103-118.

Roch, S. (2004). The new studio model. Gamasutra. http://www. gamasutra.com/features20041029/roch_01. shtml.

Rogers, D. L. (2004). The end game: How top developers sold their studios, Part 1. http://www.gamasutra.com.

Rosenkopf, L., and Nerkar, A. (2001). "Beyond local search: boundary-spanning, exploration, and impact in the optical disk industry", Strategic Management Journal, 22(4), 287-306.

Salen, K., and Zimmerman, E. (2003). Rules of Play: Fundamentals of Game Design. MIT Press Cambridge.

Sampson, R. C. (2005). "Experience effects and collaborative returns in R\&D alliances", Strategic Management Journal, 26(11), 1009-1031.

Skilton, P. F., and Dooley, K. J. (2010). "The effects of repeat collaboration on creative abrasion", Academy of Management Review, 35(1), 118-134.

Sternberg, R. J., ed. (1998). Handbook of Creativity. Cambridge University Press, Cambridge, UK.

Tschang, F. T. (2007). "Balancing the tensions between rationalization and creativity in the video games industry", Organization Science, 18(6), 989-1005.

Tunisini, A., and Zanfei, A. (1998). "Exploiting and creating knowledge through customer-supplier relationships: lessons from a case study", RED Management, 28(2), 111-118.

Uzzi, B. (1997). "Social structure and competition in interfirm networks: The paradox of embeddedness", Administrative Science Quarterly, 35-67.

Uzzi, B., and Lancaster, R. (2003). "Relational embeddedness and learning: The case of bank loan managers and their clients", Management Science, 49(4), 383-399.

Vanneste, B. S., and Puranam, P. (2010). "Repeated interactions and contractual detail: Identifying the learning effect", Organization Science, 21(1), 186-201.

Williamson, O. E. (1985). The economic institutions of capitalism. Simon and Schuster.

Williamson, O. E. (1996). The mechanisms of governance. Oxford University Press.

Wuyts, S., Stremersch, S., Van den Bulte, C., and Franses, P. H. (2004). “Vertical marketing systems for complex products: A triadic perspective", Journal of Marketing Research, 41(4), 479-487.

Wuyts, S., and Geyskens, I. (2005). “The formation of buyer - supplier relationships: detailed contract drafting and close partner selection", Journal of Marketing, 69(4), 103-117.

Zaheer, A., and Venkatraman, N. (1995). "Relational governance as an interorganizational strategy: An empirical test of the role of trust in economic exchange", Strategic Management Journal, 16(5), 373-392.

Zheng, Y., and Yang, H. (2015). "Does familiarity foster innovation? The impact of alliance partner repeatedness on breakthrough innovations", Journal of Management Studies, 52(2), 213-230.

Zollo, M., Reuer, J. J., and Singh, H. (2002). "Interorganizational routines and performance in strategic alliances", Organization Science, 13(6), 701-713. 